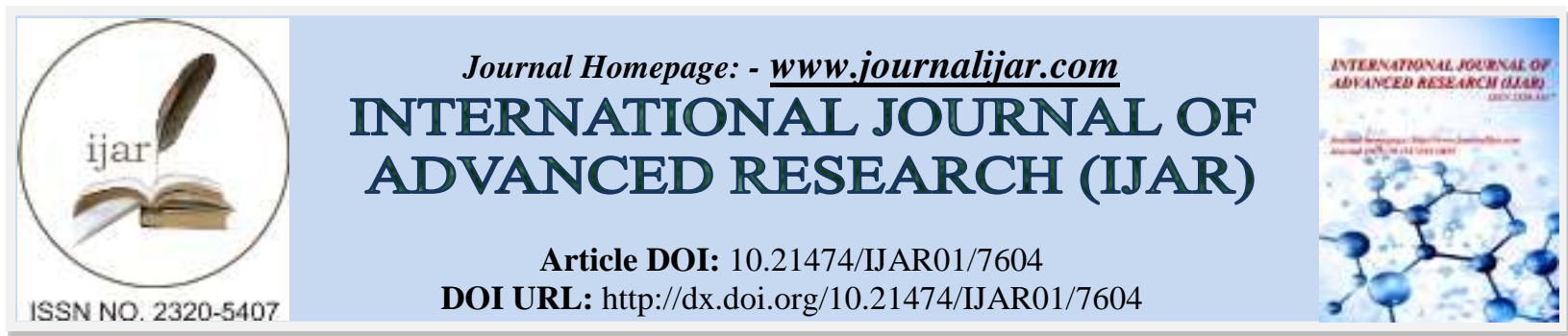

RESEARCH ARTICLE

\title{
CATHETER ASSOCIATED URINARY TRACT INFECTION (CAUTI) IN MEDICAL WARD, AND ICU KFHH DURING YEAR 2017.
}

Fawkia E. Zahran ${ }^{1}$, Amal Khaleel Abu Alhommos ${ }^{2}$, Sameh A Elkohafy ${ }^{3}$, Ahmed Ibrahim ${ }^{4}$ and Gamil K. Mohamed 5 .

1. Internal Medicine Department, Faculty of Medicine for girls,Al Azhar University, Cairo, Egypt.

2. M.Sc. clinical pharmacist, lecturer, King Faisal University, Alhasa, Saudi Arabia.

3. Lecturer of anesthesia and surgical ICU Faculty of medicine Tanta University.

4. PhD, Research \&Biostatistics Department, Prince Sultan Cardiac Center-Alhassa.

5. Cardiothoracic surgery, Faculty of medicine, Al Azhar university, Cairo, Egypt.

\section{Manuscript Info}

\section{Manuscript History}

Received: 20 June 2018

Final Accepted: 22 July 2018

Published: August 2018

Keywords:-

Adherence, prophylactic measures, Antibiotic Prophylaxis Guidelines, Surgeons, KSA, 2018.

\section{Abstract}

Background: Catheter-associated urinary tract infection (CAUTI) is one of the most common hospital acquired infection.

Objectives: determining the risk factors, causes and frequency of CAUTI among infected cases with CAUTI in King Fahad Hofuf hospital and to provide local evidence-based recommendations for prevention of CAUTI.

Methods: It is a prospective surveillance study of CAUTI. The study was carried out at the Medical ward in King Fahad Hofuf hospital (KFHH) from May to August 2017. The study included all adult patients who are admitted to medical or ICU during the study period with medical conditions rather than UTI and have been catheterized with Foley catheter. The information of the patients were collected from the medical records of the wards and day care unit.

Results: the most common causes were sepsis and pneumonia followed by hyperglycemia. Most of the patients showed no symptoms however only $4.5 \%$ have fever and there was a positive association between fever and CAUTI as a risk factor for CAUTI. About 29.55 of patients had CAUTI with the majority of them located in ward than ICU. The most common isolated organism among patients with CAUTI are Yeast, candida, E-coli and pseudomonas. The most commonly used antibiotic for CAUTI including cefatrixone, Linezolid, colisitin and fluconazole. CAUTI was significantly associated with female gender.

Conclusion: CAUTI was most common among patients located in ward than ICU. The most common risk factors were female gender, fever, previous illness and long duration of illness. Yeast and candida are the most common isolated microorganisms among patients with CAUTI. 


\section{Introduction:-}

Catheter-associated urinary tract infection (CAUTI) is one of the most common hospital acquired infection ${ }^{(\mathbf{1})}$. It is estimated for more than $30 \%$ of infections reported by acute care hospitals ${ }^{(2)}$. CAUTI is defined as a symptomatic patient with a urinary catheter (UC) had one or more of the following signs or symptoms, with no other recognized infection: fever (temperature $\geq 38^{\circ} \mathrm{C}$ ), urinary urgency, frequency, dysuria, or suprapubic tenderness, and this patient had a positive urine culture with no more than two pathogens isolated. Or a patient with a UC had at least two of the following signs or symptoms, with no other recognized infection: fever (temperature $\geq 38{ }^{\circ} \mathrm{C}$ ), urinary urgency, frequency, dysuria, or suprapubic tenderness, and one of the following: positive dipstick analyses for leukocyte esterase or nitrate, pyuria (urine specimen with $\geq 10 \mathrm{WBC} / \mathrm{mm} 3$ a pathogen observed on Gram staining of midstream urine, and the physician instituted appropriate therapy for a urinary tract infection ${ }^{(3,4)}$.

The impact of a UTI on the individual can vary greatly, depending on age, co-morbidities and socio-economic circumstances. CAUTIs may lead to unnecessary use of antibiotics and antimicrobial resistance and longer hospital stays ${ }^{(4)}$. Virtually CAUTI is caused by instrumentation of the urinary tract and has been associated with increased morbidity, mortality, hospital cost, and length of stay ${ }^{(\mathbf{5})}$.

It causes secondary nosocomial bloodstream infection as $17 \%$ of nosocomial bacteremia originated from urinary with an associated mortality of $10 \%$. However, $17 \%$ and $69 \%$ of CAUTI can be prevented through implementation of evidence-based bundle for CAUTI ${ }^{(6)}$. This study aimed at determining the risk factors, causes and frequency of CAUTI among infected cases with CAUTI in King Fahad Hofuf hospital and to provide local evidence-based recommendations for prevention of CAUTI.

\section{Methods:-}

\section{Study design:}

It is a prospective surveillance study of CAUTI.

\section{Study setting:}

The study was carried out at the Medical ward in King Fahad Hofuf hospital (KFHH) from May to August 2017. The bed capacity of about 210 bed include 15 bed in adult medical ICU, Bed occupancy rate $61.2 \%$ in medical ward and $100 \%$ in medical ICU, estimated average length of stay in medical ward about 4.9 days and medical ICU 9.8 day

\section{Study population:}

The study included all adult patients who are admitted to medical or ICU during the study period with medical conditions rather than UTI and have been catheterized with Foley catheter. The exclusion criteria were patient admitted with community acquired UTI, Foley catheter and those who are transferred from other hospital with indwelling urinary catheter.

\section{Study tools and data collection:}

The information of the patients were collected from the medical records of the wards and day care unit. The collected data included information on the demographic, clinical data, type and cause of admission, co-morbidities, risk factors, causes of urinary catheterization, number of patients who had any type of infection at admission, duration of devices use, number of days each Foley catheter use, type Foley catheter, date of infection, type of isolated pathogen contribute to infection, antibiogram, prescribed antibiotic, dose and duration of antibiotics, length of hospital stay and outcome of CAUTI management..

Also, the main outcome measures will include the suitability of indicted prophylactic antibiotic, the antibiotic choice, dosage of administration, timing and duration.

\section{Ethical considerations:-}

A written approval was provided from the ethic committee in KFHH the aim of the study and research proposal. Oral or informed contest were given by all patients enrolled in the study. 


\section{Statistical analysis:}

The data processing was done using SPSS version 20. Descriptive statistics were presented as percentages and frequencies. The Chi squared test was used to detect any significant difference between categorical variables. $\mathrm{P}$ value significance level 0.05 and $95 \%$ confidence intervals are considered as significant.

\section{Results:-}

Table $1 \& 2$ showed the demographic characteristics of the included patients as age, gender and body mass index (BMI) (Figure. 1 \&2).

Table 1:- Demographic characteristics of the included patients:

\begin{tabular}{|l|l|l|}
\hline & No. & \% \\
\hline Age group & \multicolumn{1}{|l|}{} \\
\hline$<40$ & 18 & 9.0 \\
\hline $40-60$ & 44 & 22.0 \\
\hline $60-80$ & 96 & 48.0 \\
\hline $80+$ & 42 & 21.0 \\
\hline Range & $14.0-101$ & \\
Mean \pm S.D. & $66.83 \pm 17.78$ & \\
\hline Sex & \multicolumn{2}{|l|}{} \\
\hline Male & 55 & 27.5 \\
\hline Female & 144 & 72.0 \\
\hline BMI & & \\
\hline Under weight & 44 & 22.0 \\
\hline Normal weight & 64 & 32.0 \\
\hline Over weight & 62 & 31.0 \\
\hline Obese/morbid obese & 30 & 15.0 \\
\hline Range & $15.6-54.8$ & \\
Mean \pm S.D. & $27.4 \pm 6.21$ & \\
\hline & & \\
\hline
\end{tabular}

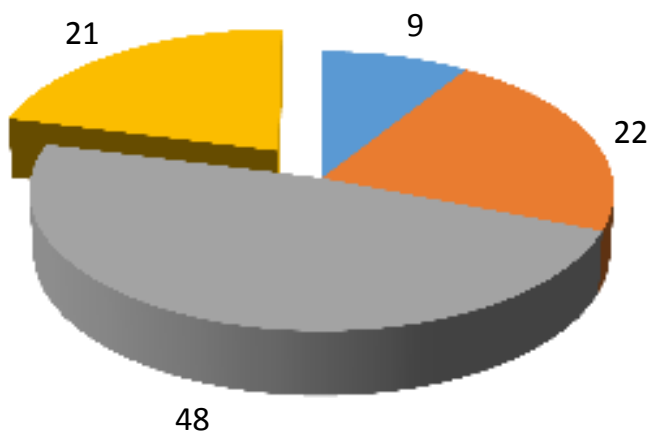

Age group 


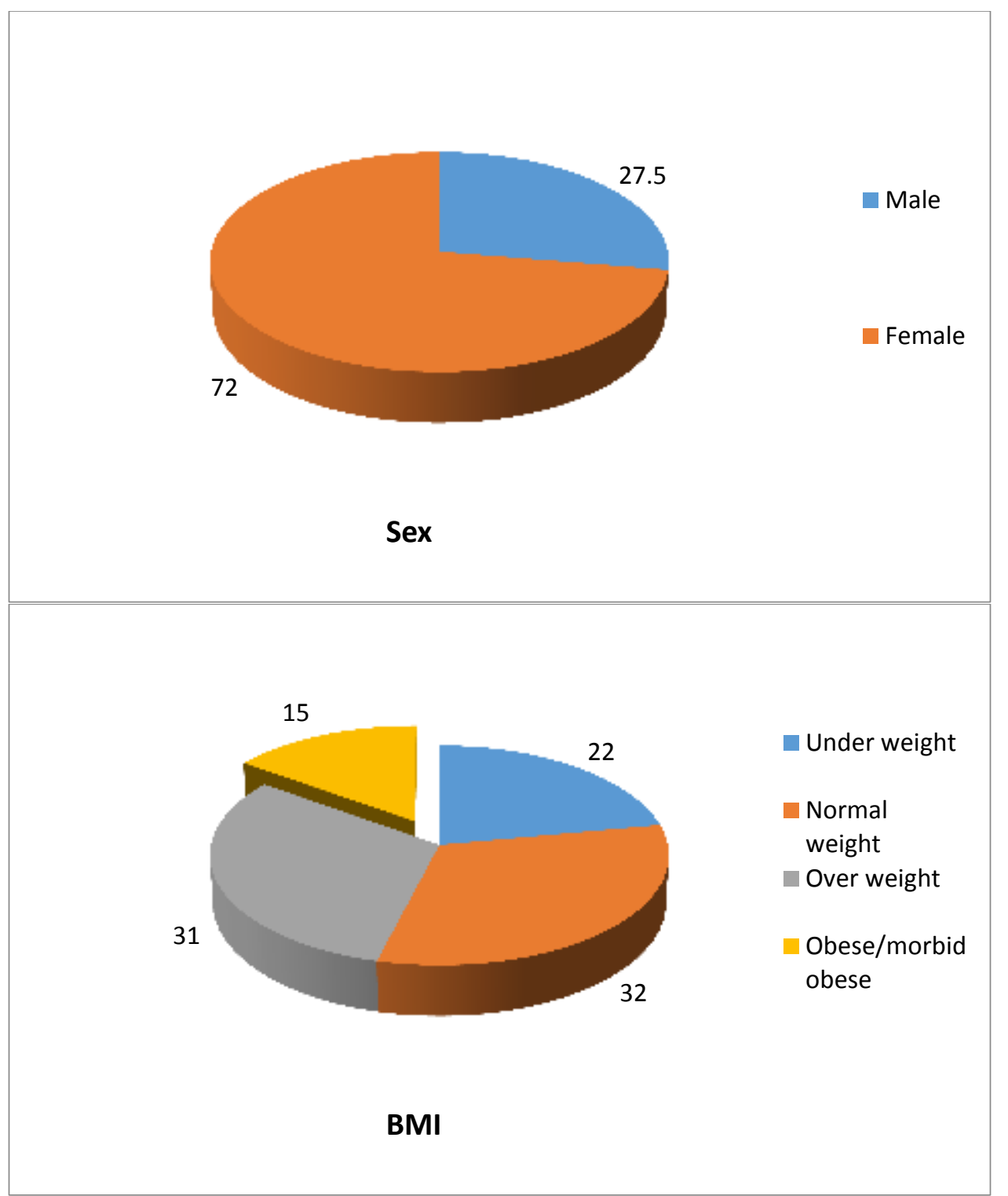

Fig 1:- Demographic data of the studied patients group.

The cause of admission and associated disease:

The cause of admission to the hospital was shown in table 2 and the most common causes were sepsis and pneumonia followed by hyperglycemia. Most of the patients have no associated disease (35\%) but $22 \%$ have diabetes with hypertension and $10 \%$ have diabetes only (Table. 3 ).

Table 2:- Distribution of the studied patients regarding the cause of admission:

\begin{tabular}{|c|c|c|}
\hline Cause of admission & Frequency & Percent \\
\hline Acute confusional state & 1 & .5 \\
\hline Acute GE & 2 & 1.0 \\
\hline Acute Heamorrhagic strock & 1 & .5 \\
\hline AKI & 1 & .5 \\
\hline Anaemia & 3 & 1.5 \\
\hline Anorexia dehydration & 2 & 1.0 \\
\hline Ascites & 2 & 1.0 \\
\hline Aspiration syndrome & 5 & 2.5 \\
\hline CAP & 2 & 1.0 \\
\hline
\end{tabular}




\begin{tabular}{|l|l|l|}
\hline CHF & 17 & 8.5 \\
\hline Coma & 1 & .5 \\
\hline COPD & 12 & 6.0 \\
\hline CVA & 16 & 8.0 \\
\hline DCMP & 1 & .5 \\
\hline Dehydration & 3 & 1.5 \\
\hline Dilated cardiomyopathy & 1 & .5 \\
\hline DKA & 2 & 1.0 \\
\hline Drug overdose & 2 & 1.0 \\
\hline Electric shock & 1 & .5 \\
\hline Epilepsy & 3 & 1.5 \\
\hline Fever of unkown origin & 1 & .5 \\
\hline Heart Failure & 2 & 1.0 \\
\hline Hepatic encephalopathy & 2 & 1.0 \\
\hline HTN & 1 & .5 \\
\hline Hyperglycaemia & 22 & 11.0 \\
\hline Hypoglycaemia & 2 & 1.0 \\
\hline Hyponatraemia & 2 & 1.0 \\
\hline Hypoventelation syndrome & 1 & .5 \\
\hline Infected bed sores & 7 & 3.5 \\
\hline Lung abscess & 1 & .5 \\
\hline Melena & 3 & 1.5 \\
\hline Obstructive sleep apnea & 1 & .5 \\
\hline Pericardil effusion & 1 & .5 \\
\hline Pneumonia & 24 & 12.0 \\
\hline Pulmonary fibrosis & 3 & 1.5 \\
\hline SCD & 4 & 2.0 \\
\hline Sepesis & 3 & 1.5 \\
\hline Sepsis & 28 & 14.0 \\
\hline Septic shock & 9 & 4.5 \\
\hline Syncopal attack & 1 & .5 \\
\hline Type 2 respiratory failure & 2 & 1.0 \\
\hline Warfarin overdose & 2 & 1.0 \\
\hline Total & 200 & 100.0 \\
\hline
\end{tabular}

Table 3:- Distribution of the studied patients regarding the associated disease:

\begin{tabular}{|c|c|c|}
\hline & Frequency & Percent \\
\hline No associated disease & 70 & 35.0 \\
\hline Bedridden & 1 & .5 \\
\hline CKD & 1 & .5 \\
\hline CKD-DM-HTN & 1 & .5 \\
\hline CKD-IHD & 1 & .5 \\
\hline CVA & 7 & 3.5 \\
\hline CVA-bedridden & 1 & .5 \\
\hline CVA-DM-HTN & 1 & .5 \\
\hline DM & 20 & 10.0 \\
\hline DM- HTN & 6 & 3.0 \\
\hline DM-AF-IHD & 1 & .5 \\
\hline DM-CKD & 2 & 1.0 \\
\hline DM-CVA & 1 & .5 \\
\hline DM-HTN & 45 & 22.5 \\
\hline DM-HTN-CKD & 2 & 1.0 \\
\hline DM-HTN-COPD & 2 & 1.0 \\
\hline DM-HTN-CVA & 4 & 2.0 \\
\hline
\end{tabular}




\begin{tabular}{|l|l|l|}
\hline DM-HTN-HCV & 2 & 1.0 \\
\hline DM-HTN-IHD & 5 & 2.5 \\
\hline Epilepsy & 7 & 3.5 \\
\hline HCV-DM & 1 & .5 \\
\hline HTN & 9 & 4.5 \\
\hline HTN- RF & 1 & .5 \\
\hline HTN-CKD & 1 & .5 \\
\hline IHD & 2 & 1.0 \\
\hline MR- Epilepsy & 2 & 1.0 \\
\hline Old CVA & 2 & 1.0 \\
\hline Pancreatic cancer & 1 & .5 \\
\hline Renal impairment & 1 & .5 \\
\hline Total & 200 & 100.0 \\
\hline
\end{tabular}

\section{Base line and past history:}

The majority of patients have no past history of UTI, with negative urine analysis among all the patients. The other variables are presented in table. $4 \&$ Figure. 2).

Table 4:- Distribution of the studied patients regarding the clinical data at base line and past history.

\begin{tabular}{|l|l|l|}
\hline & No. & \% \\
\hline Past history Of UTI & & \\
\hline Yes & 20 & 10.0 \\
\hline No & 180 & 90.0 \\
\hline Base line urine analysis & & \\
\hline Positive & 0 & 0.0 \\
\hline Negative & 200 & 100.0 \\
\hline Past history of FC & & \\
\hline Yes & 25 & 12.5 \\
\hline No & 174 & 87.0 \\
\hline Type of FC & & \\
\hline S & 200 & 100.0 \\
\hline Previous operation & & \\
\hline Yes & 24 & 12.0 \\
\hline No & 176 & 88.0 \\
\hline
\end{tabular}

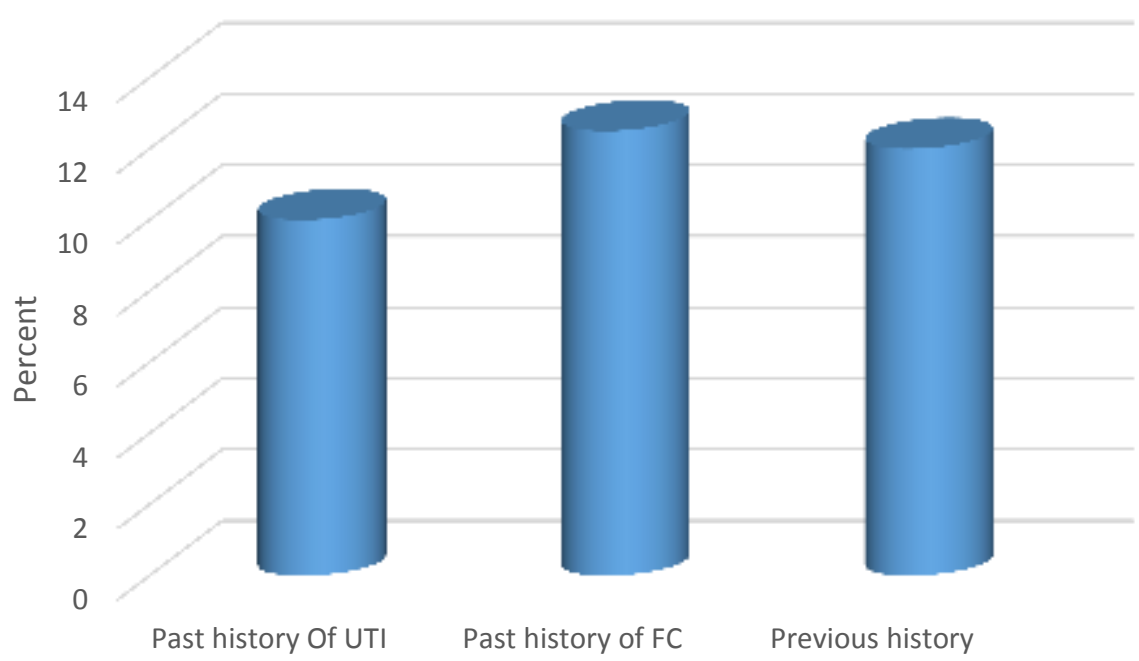

Fig. 2:- Distribution of the studied patients regarding the past history of UTI and F.C. 
The symptoms of the studied patients:

Most of the patients showed no symptoms however only $4.5 \%$ have fever (Table .5, figure. 3 )

Table 5:- Distribution of the studied patients regarding the symptoms.

\begin{tabular}{|l|l|l|}
\hline & No. & \% \\
\hline Fever & 9 & 4.5 \\
\hline Suprapubic pain & 2 & 1.0 \\
\hline $\begin{array}{l}\text { Costophrenic angle pain or } \\
\text { tenderness }\end{array}$ & 3 & 1.5 \\
\hline Urinary urgency & 2 & 1.0 \\
\hline Urinary frequency & 0 & 0.0 \\
\hline Dysuria & 1 & 0.5 \\
\hline Hematuria Vomiting & 2 & 1.0 \\
\hline Confusion & 3 & 1.5 \\
\hline Fatigue & 0 & 0.0 \\
\hline
\end{tabular}

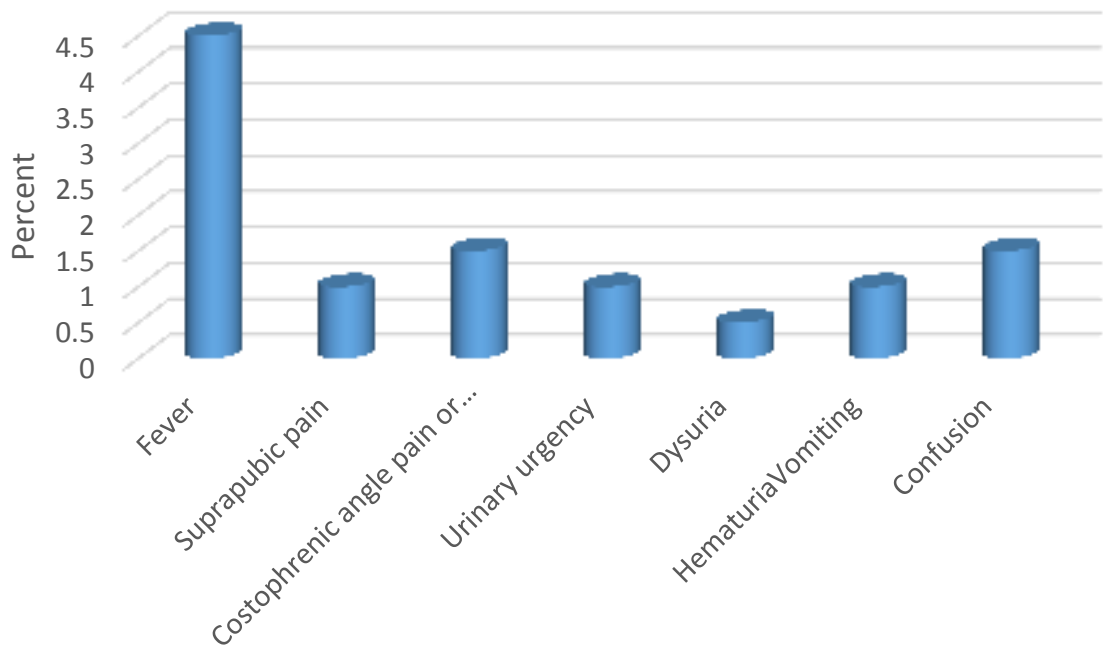

Fig. 3:- Distribution of the studied patients regarding the symptoms

Catheter-associated urinary tract infection:

Most of the patients showed no signs of CAUTI (70.5\%) while $29.5 \%$ had positive signs for CAUTI.

Table 6:- Distribution of the studied patients regarding Catheter-associated urinary tract infection.

\begin{tabular}{|l|l|l|}
\hline & No. & $\%$ \\
\hline $\begin{array}{l}\text { Catheter-associated urinary tract } \\
\text { infection. }\end{array}$ & & \\
\hline$+\mathrm{ve}$ & 59 & 29.5 \\
\hline -ve & 141 & 70.5 \\
\hline
\end{tabular}




\section{Positive Negative}

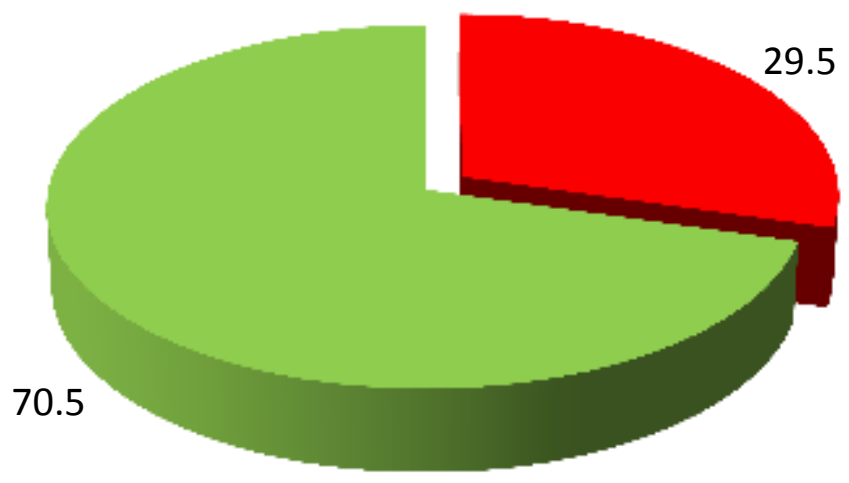

\section{Catheter-associated urinary tract infection}

Fig. 4:- Distribution of the studied patients regarding catheter-associated urinary tract infection.

The type of isolated organism associated from urinary tract infection:

The most common isolated organism among patients with CAUTI are Yeast, candida, E-coli and pseudomonas.

Table 7:- Distribution of positive cases catheter associated urinary tract infection regarding the type of isolated organism

\begin{tabular}{|l|l|l|}
\hline & Number & Percent \\
\hline Type of isolated organism & & \\
\hline Acinetobacter & 1 & 1.7 \\
\hline Candida & 11 & 18.6 \\
\hline E.Coli & 7 & 11.9 \\
\hline Enterococcus faecalis feacalis+ & 1 & 1.7 \\
\hline $\begin{array}{l}\text { Enterococcus } \\
\text { Pseudomonas }\end{array}$ & 1 & 1.7 \\
\hline Klebsiella & 2 & 3.4 \\
\hline Proteus & 1 & 1.7 \\
\hline Pseudomonas & 4 & 6.8 \\
\hline Streptococcus & 1 & 1.7 \\
\hline Vancomycin resistant enterococcus & 4 & 6.8 \\
\hline Yeast & 26 & 44.1 \\
\hline Total & 59 & 100.0 \\
\hline
\end{tabular}




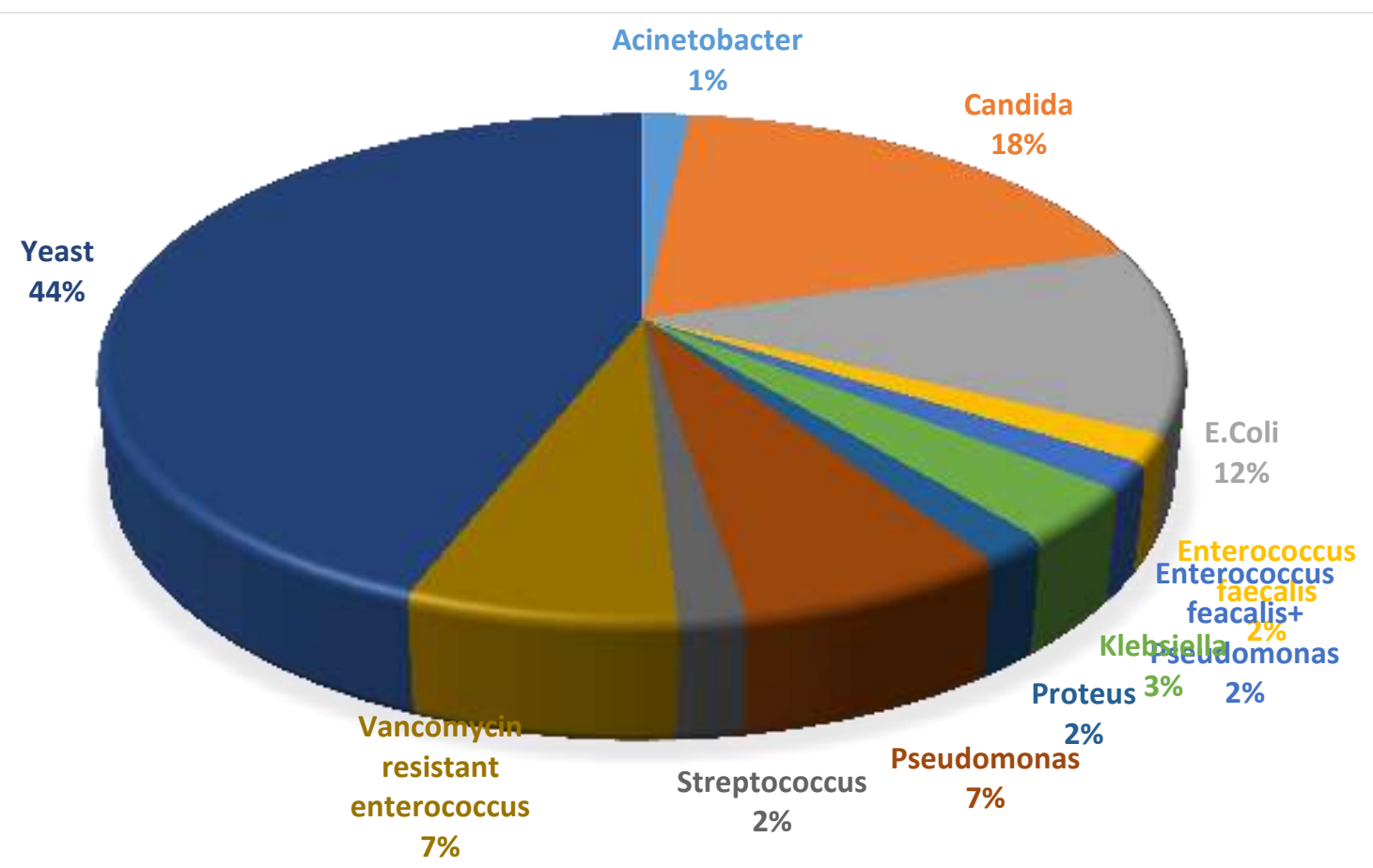

Fig. 5:- Distribution of positive cases catheter associated urinary tract infection regarding the type of isolated organism

The type of treatment of CAUTI:

Table 8 showed that the most commonly used antibiotic for CAUTI including cefatrixone, Linezolid, colisitin and fluconazole (Table. 8 \& Figure. 6).

Table 8:- Distribution of positive cases catheter associated urinary tract infection regarding the type of treatment

\begin{tabular}{|l|l|l|}
\hline Antibiotic received & Number & Percent \\
\hline Amikacin & 1 & 4 \\
\hline Amikacin-Meropenum & 1 & 4 \\
\hline Augmentin & 1 & 4 \\
\hline Cefatrioxon & 6 & 24 \\
\hline Colistin & 3 & 12 \\
\hline Fluconazole & 3 & 12 \\
\hline Imipenem & 3 & 12 \\
\hline Linezolid & 4 & 16 \\
\hline Meropenum & 2 & 8 \\
\hline Meropenum-Vancomycin & 1 & 4 \\
\hline Total & 25 & 100.0 \\
\hline
\end{tabular}




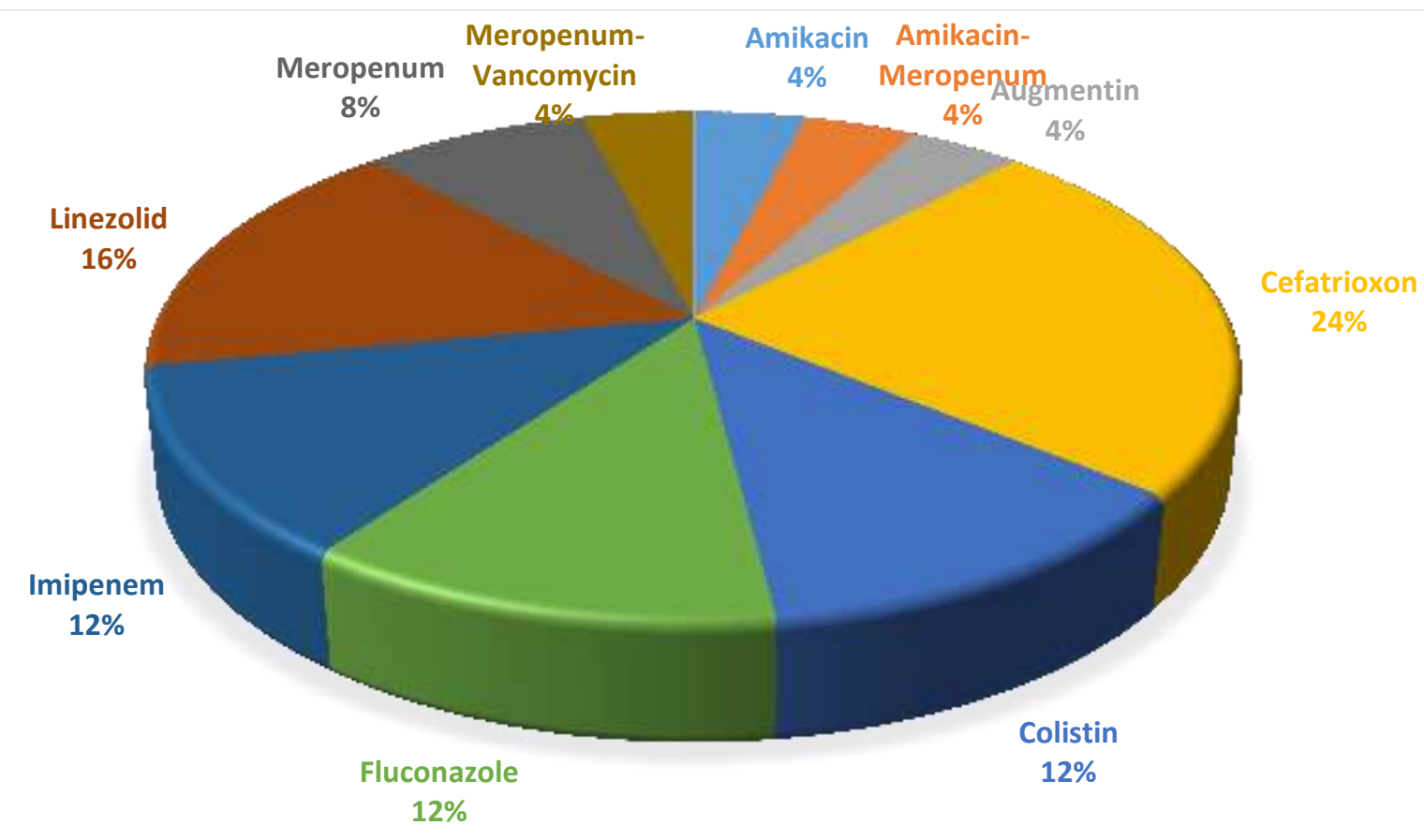

Fig. 6:- Distribution of positive cases catheter associated urinary tract infection regarding the type of treatment

The outcomes:

The outcomes of CAUTI were complete recovery among 98.5\% of patients (table. 9, Figure. 7)

Table 9:- Distribution of the studied patients group regarding outcome.

\begin{tabular}{|l|l|l|}
\hline & Number & Percent \\
\hline Out come & & \\
\hline complete recovery & 197 & 98.5 \\
\hline Discharge against medical advice & 1 & .5 \\
\hline Died & 2 & 1.0 \\
\hline Total & 200 & 100.0 \\
\hline
\end{tabular}




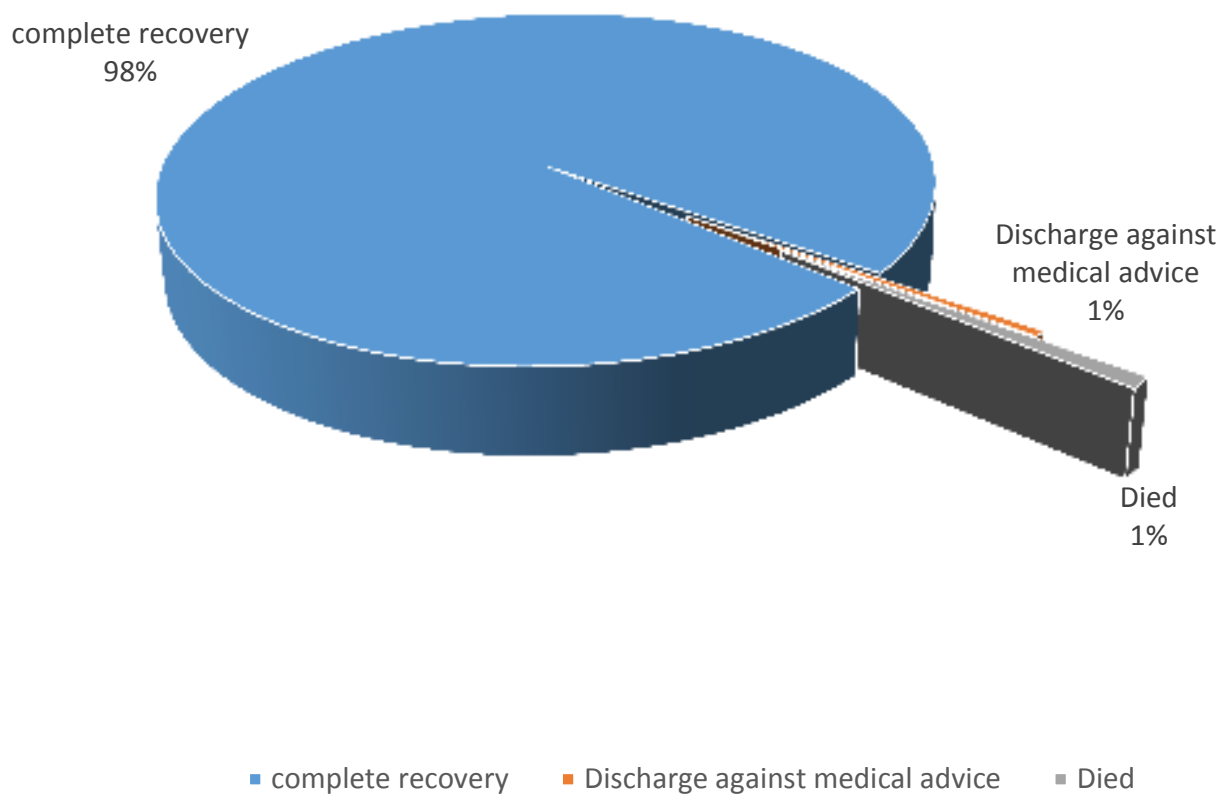

Fig. 7:- Distribution of the studied patients group regarding outcome.

Distribution of the studied patients group regarding to their location:

Table. 10 showed the distribution of the patients regarding their location as $82.5 \%$ were in medical ward and $17.5 \%$ were in ICU.

Table 10:- Distribution of the studied patients group regarding to their location

\begin{tabular}{|l|l|l|}
\hline & Number & Percent \\
\hline Location & & \\
\hline ICU & 35 & 17.5 \\
\hline Ward & 165 & 82.5 \\
\hline Total & 200 & 100.0 \\
\hline
\end{tabular}


ICU ward

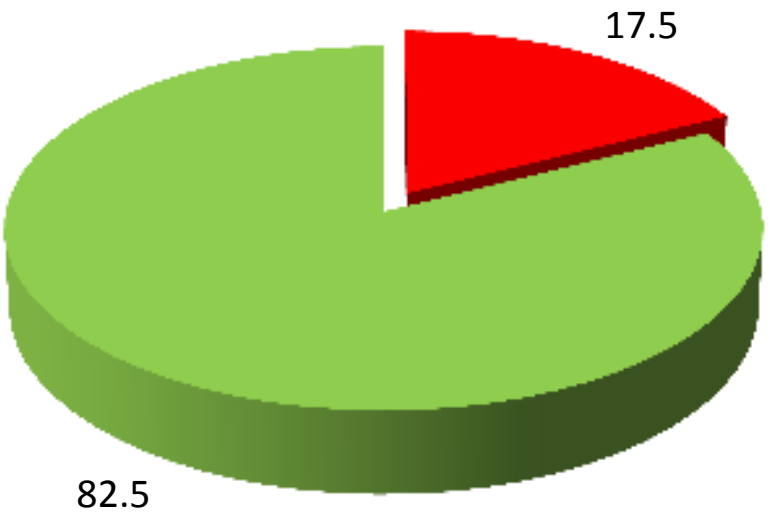

\section{Location}

Fig. 8:- Distribution of the studied patients group regarding to their location

Relation between catheter-associated urinary tract infection and demographic data as a risk factors:

There was no correlation between the CAUTI with the age, BMI, PH of UTI, past history of FC. On the other hand, it was significantly associated with female gender and the type of associated disease.

Table 11:- Relation between catheter-associated urinary tract infection and demographic data as a risk factors.

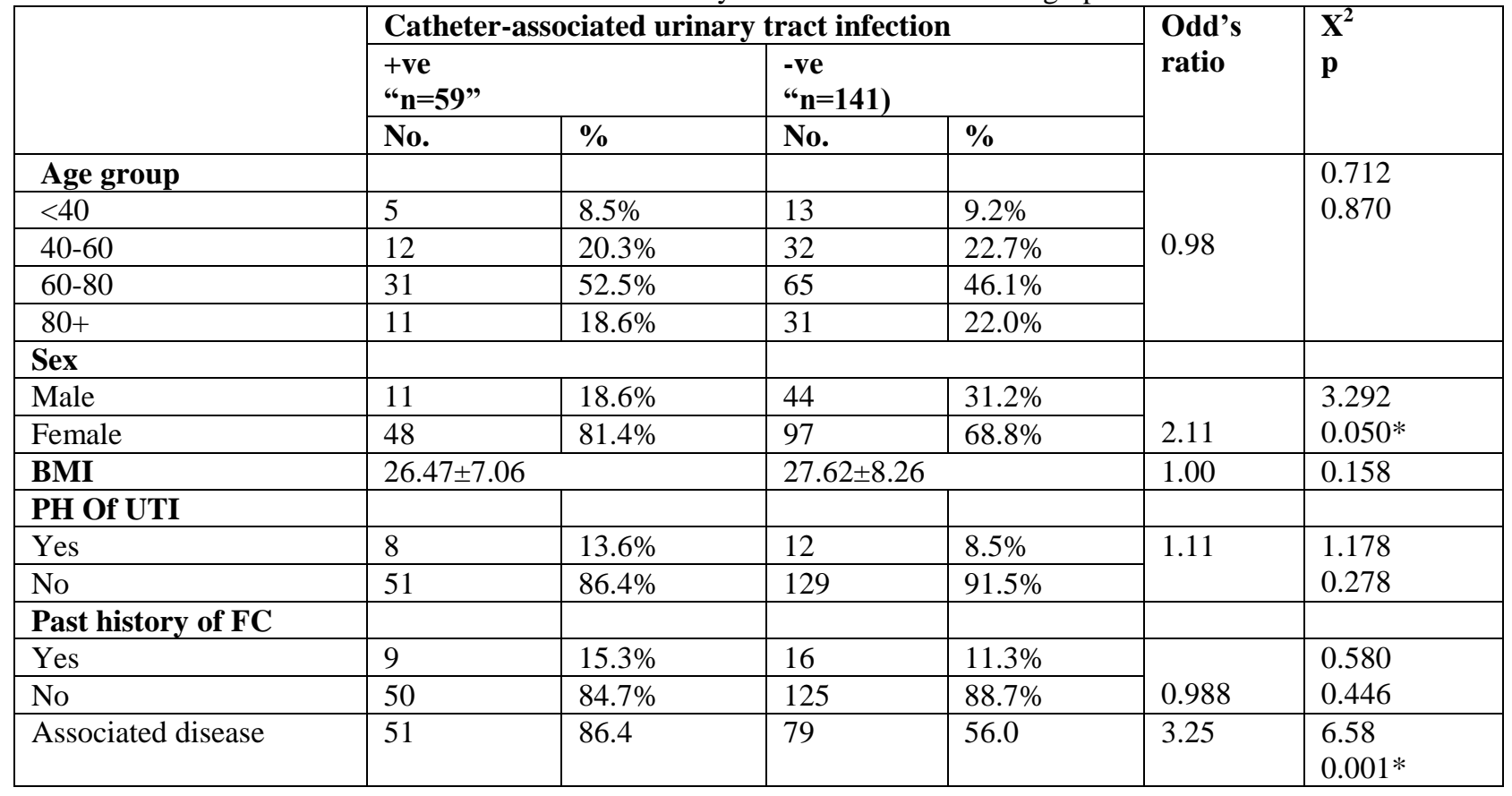


Relation between catheter-associated urinary tract infection and symptoms:

There was no correlation between the CAUTI with the symptoms among patients including fever, urinary urgency, hematouria vomiting and confusion while other symptoms showed no association with CAUTI.

Table 12:- Relation between catheter-associated urinary tract infection and symptoms.

\begin{tabular}{|c|c|c|c|c|c|c|}
\hline & \multicolumn{4}{|c|}{ Catheter-associated urinary tract infection } & \multirow{3}{*}{$\begin{array}{l}\text { Odd's } \\
\text { ratio }\end{array}$} & \multirow{3}{*}{$\begin{array}{l}\mathbf{X}^{2} \\
\mathbf{p}\end{array}$} \\
\hline & \multicolumn{2}{|c|}{$\begin{array}{l}+v e \\
\text { "n=59" }\end{array}$} & \multicolumn{2}{|c|}{$\begin{array}{l}\text {-ve } \\
\text { "n=141) }\end{array}$} & & \\
\hline & No. & $\%$ & No. & $\%$ & & \\
\hline Fever & 8 & $13.6 \%$ & 1 & $0.7 \%$ & 3.92 & $\begin{array}{c}15.982 \\
0.0001 *\end{array}$ \\
\hline Suprapubic pain & 1 & $1.7 \%$ & 1 & $0.7 \%$ & 1.22 & $\begin{array}{l}1.25 \\
0.089 \\
\end{array}$ \\
\hline $\begin{array}{l}\text { Costophrenic angle pain } \\
\text { or tenderness }\end{array}$ & 2 & $3.4 \%$ & 1 & $0.7 \%$ & 1.31 & $\begin{array}{l}2.023 \\
0.155\end{array}$ \\
\hline Urinary urgency & 2 & $3.4 \%$ & 0 & $0.0 \%$ & 2.65 & $\begin{array}{l}4.828 \\
0.028 *\end{array}$ \\
\hline Dysuria & 1 & $1.7 \%$ & 0 & $0.0 \%$ & 1.00 & $\begin{array}{l}2.402 \\
0.121\end{array}$ \\
\hline HematuriaVomiting & 2 & $3.4 \%$ & 0 & $0.0 \%$ & 2.65 & $\begin{array}{l}4.828 \\
0.028 *\end{array}$ \\
\hline Confusion & 3 & $5.1 \%$ & 0 & $0.0 \%$ & 2.98 & $\begin{array}{l}7.279 \\
0.007 *\end{array}$ \\
\hline
\end{tabular}

Relation between catheter-associated urinary tract infection and duration of treatment as a risk factors:

There was a highly significant association between the duration of treatment and the CAUTI as the higher the treatment period the higher the risk of CAUTI.

Table 13:- Relation between catheter-associated urinary tract infection and duration of treatment as a risk factors.

\begin{tabular}{|c|c|c|c|c|c|c|}
\hline \multirow[t]{3}{*}{ Duration of treatment } & \multicolumn{4}{|c|}{ Catheter-associated urinary tract infection } & Odd's ratio & \multirow{3}{*}{$\begin{array}{l}X^{2} \\
p\end{array}$} \\
\hline & \multicolumn{2}{|c|}{$\begin{array}{l}+\mathrm{ve} \\
\text { "n=59" }\end{array}$} & \multicolumn{2}{|c|}{$\begin{array}{l}-\mathrm{ve} \\
\text { “n=141) }\end{array}$} & & \\
\hline & No. & $\%$ & No. & $\%$ & & \\
\hline$<7$ days & 3 & 5.1 & 45 & 31.9 & & 12.52 \\
\hline $7-14$ days & 2 & 3.4 & 52 & 36.9 & & $0.001 *$ \\
\hline 14-30 days & 18 & 30.5 & 15 & 10.6 & & \\
\hline$>30$ days & 36 & 61.0 & 29 & 20.6 & 3.11 & \\
\hline
\end{tabular}

Relation between catheter-associated urinary tract infection and outcome:

There was no correlation between the outcomes of treatment and the CAUTI.

Table 14:- Relation between catheter-associated urinary tract infection and outcome.

\begin{tabular}{|c|c|c|c|c|c|c|}
\hline \multirow[t]{3}{*}{ Outcome } & \multicolumn{4}{|c|}{ Catheter-associated urinary tract infection } & \multirow{3}{*}{$\begin{array}{l}\text { Odd's } \\
\text { ratio }\end{array}$} & \multirow{3}{*}{$\begin{array}{l}X^{2} \\
p\end{array}$} \\
\hline & \multicolumn{2}{|c|}{$\begin{array}{l}\text { +ve } \\
\text { "n=59" }\end{array}$} & \multicolumn{2}{|c|}{$\begin{array}{l}\text {-ve } \\
\text { " } n=141)\end{array}$} & & \\
\hline & No. & $\%$ & No. & $\%$ & & \\
\hline complete recovery & 58 & 98.3 & 139 & 98.6 & \multirow{3}{*}{0.98} & \multirow{3}{*}{$\begin{array}{l}1.068 \\
0.586\end{array}$} \\
\hline $\begin{array}{ll}\text { Discharge } & \text { against } \\
\text { medical advice }\end{array}$ & 0 & 0.0 & 1 & 0.7 & & \\
\hline Died & 1 & 1.7 & 1 & 0.7 & & \\
\hline
\end{tabular}

\section{Discussion:-}

Urinary tract is recurrently exposed to colonization of numerous usual flora some of which can act as adaptable pathogens ${ }^{(7)}$. Urinary Tract Infection (UTI) is a comprehensive term that describes a group of diseases that can 
result from the settlement of microbes in the urinary tract ${ }^{(8)}$. UTI consist of a multiple of disease including urethritis, pyelonephritis and cystitis ${ }^{(8)}$.

UTIs continue is a serious risk to millions of cases per year with possibility of evolving many chronic diseases ${ }^{\left({ }^{9}\right)}$. It can also have a significant impact on the socioeconomic lives of affected individuals, contributing largely to the increase in the consumption of antimicrobial drugs ${ }^{(\mathbf{1 0}, \mathbf{1 1})}$. Many complications can originate from using indwelling bladder catheter ${ }^{(\mathbf{1 2})}$.

This study showed that the most common causes were sepsis and pneumonia followed by hyperglycemia. In consistence, most of CAUTI patients fever has many causes of admission including pneumonia, bloodstream infection, or an intracranial bleed ${ }^{(13)}$. This is also in the same pattern with other previous studies ${ }^{(14,15)}$.

Most of the patients showed no symptoms however only $4.5 \%$ have fever and there was a positive association between fever and CAUTI as a risk factor for CAUTI. In accordance, Fever is particularly communal among critically ill patients also catheterized patients must be evaluated for CAUTI if fever presented ${ }^{(13,16,17)}$.

About 29.55 of patients had CAUTI with the majority of them located in ward than ICU. The same results were shown in other reports as about $75 \%$ of CAUTIs occurred in ward but not in ICU patients ${ }^{(18)}$. In the same respect, many studies showed that more than half of CAUTI patients were located in non-ICU wards ${ }^{(\mathbf{1 9}, \mathbf{2 0})}$.

The most common isolated organism among patients with CAUTI are Yeast, candida, E-coli and pseudomonas. Also, Yeast has been found to regularly colonize in the urinary catheters in about $50 \%$ of CAUTI ${ }^{(\mathbf{1 3})}$. Another study showed that the most common pathogens isolated from CAUTI patients were Escherichia coli, enterococci and Candida species ${ }^{(\mathbf{1 8})}$.

The most commonly used antibiotic for CAUTI including cefatrixone, Linezolid, colisitin and fluconazole. However, there is no recommendation for antibiotic prophylaxis can be specified for repetitive use for prevention of CAUTI ${ }^{(21)}$.

CAUTI was significantly associated with female gender. Similar results were shown by kashef et al. (2010) (22) where $85.2 \%$ of females had UTI. Also, another study proposed that more than half of patients were females ${ }^{(23)}$ as the anatomical structure of the female genitourinary tract makes them more susceptible to the disease, particularly during pregnancy ${ }^{(\mathbf{1 0}, \mathbf{2 4})}$.

\section{Conclusion:-}

CAUTI was most common among patients located in ward than ICU. The most common risk factors were female gender, fever, previous illness and long duration of illness. Yeast and candida are the most common isolated microorganisms among patients with CAUTI.

Funding: This research was funded by the authors.

Acknowledgments: the authors were supported by Dr: Doa salah El- Deen

Assistant professor internal medicine and Dr. Naif S. Al-Ghamdi ,Senior medical resident 3rd year of internal medicine saudi board.

Conflicts of Interest: No conflicts of interest 


\section{References:-}

1. Conover MS, Flores-Mireles AL, Hibbing ME, et al. (2015): Establishment and Characterization of UTI and CAUTI in a Mouse Model. J Vis Exp, e52892.

2. Klevens RM, Edwards JR, Richards Jr CL, et al. (2007): Estimating health care-associated infections and deaths in US hospitals, 2002. Public health reports, 122:160-166.

3. Zielinski MD, Kuntz MM, Polites SF, et al. (2015): A prospective analysis of urinary tract infections among elderly trauma patients. The journal of trauma and acute care surgery, 79:638-642.

4. Hatachi T, Tachibana $\mathbf{K}$ and Takeuchi $\mathbf{M}$ (2015): Incidences and influences of device-associated healthcareassociated infections in a pediatric intensive care unit in Japan: a retrospective surveillance study. J Intensive Care, 3:44.

5. Tatham M, Macfarlane G, MacRae M, et al. (2015): Development and Implementation of a Catheter Associated Urinary Tract Infection (CAUTI) 'Toolkit'. BMJ quality improvement reports, 4.

6. Schaeffer AJ (2003): The direct costs of nosocomial catheter-associated urinary tract infection in the era of managed care. The Journal of urology, 170:339.

7. Rahman SR, Ahmed MF and Begum A (2014): Occurrence of urinary tract infection in adolescent and adult women of shanty town in Dhaka City, Bangladesh. Ethiopian journal of health sciences, 24:145-152.

8. Kunin CM (1994): Urinary tract infections in females. Clin Infect Dis, 18:1-10; quiz 11-12.

9. Hancock V, Ferrieres $\mathbf{L}$ and Klemm $\mathbf{P}$ (2007): Biofilm formation by asymptomatic and virulent urinary tract infectious Escherichia coli strains. FEMS microbiology letters, 267:30-37.

10. Shahina Z, Islam MJ, Abedin J, et al. (2011): A Study of Antibacterial Susceptibility and Resistance Pattern of E. coli Causing Urinary Tract Infection in Chittagong, Bangladesh. Asian J Biol Sci, 4:548-555.

11. Dada-Adegbola HO and Muili KA (2010): Antibiotic susceptibility pattern of urinary tract pathogens in Ibadan, Nigeria. African journal of medicine and medical sciences, 39:173-179.

12. Foxman B (2002): Epidemiology of urinary tract infections: incidence, morbidity, and economic costs. Am J Med, 113 Suppl 1A:5s-13s.

13. Tedja R, Wentink J, O'Horo JC, et al. (2015): Catheter-Associated Urinary Tract Infections in Intensive Care Unit Patients. Infect Control Hosp Epidemiol, 36:1330-1334.

14. Hartley S, Valley S, Kuhn L, et al. (2013): Inappropriate testing for urinary tract infection in hospitalized patients: an opportunity for improvement. Infect Control Hosp Epidemiol, 34:1204-1207.

15. Neelakanta A, Sharma S, Kesani VP, et al. (2015): Impact of changes in the NHSN catheter-associated urinary tract infection (CAUTI) surveillance criteria on the frequency and epidemiology of CAUTI in intensive care units (ICUs). Infect Control Hosp Epidemiol, 36:346-349.

16. Hooton TM, Bradley SF, Cardenas DD, et al. (2010): Diagnosis, prevention, and treatment of catheterassociated urinary tract infection in adults: 2009 International Clinical Practice Guidelines from the Infectious Diseases Society of America. Clin Infect Dis, 50:625-663.

17. Matthews SJ and Lancaster JW (2011): Urinary tract infections in the elderly population. The American journal of geriatric pharmacotherapy, 9:286-309.

18. Lewis SS, Knelson LP, Moehring RW, et al. (2013): Comparison of Non-Intensive Care Unit (ICU) versus ICU Rates of Catheter-Associated Urinary Tract Infection in Community Hospitals. Infection control and hospital epidemiology : the official journal of the Society of Hospital Epidemiologists of America, 34:744-747.

19. Weber DJ, Sickbert-Bennett EE, Gould CV, et al. (2011): Incidence of catheter-associated and non-catheterassociated urinary tract infections in a healthcare system. Infect Control Hosp Epidemiol, 32:822-823.

20. Dudeck MA, Horan TC, Peterson KD, et al. (2011): National Healthcare Safety Network (NHSN) Report, data summary for 2010, device-associated module. Am J Infect Control, 39:798-816.

21. Yamamoto S (2016): Prevention and treatment of complicated urinary tract infection. Urological Science, 27:186-189.

22. Kashef N, Djavid GE and Shahbazi S (2010): Antimicrobial susceptibility patterns of community-acquired uropathogens in Tehran, Iran. The Journal of Infection in Developing Countries, 4:202-206.

23. Tayal R, Baveja S and De A. Analysis of biofilm formation and antibiotic susceptibility pattern of uropathogens in patients admitted in a tertiary care hospital in India2015 October 1, 2015. 247-252 p.

24. Manges AR, Tabor H, Tellis P, et al. (2008): Endemic and epidemic lineages of Escherichia coli that cause urinary tract infections. Emerg Infect Dis, 14:1575-1583. 